\title{
Free Kappa Light Chain to Free Lambda Light Chain Ratio Measurement
}

National Cancer Institute

\section{Source}

National Cancer Institute. Free Kappa Light Chain to Free Lambda Light Chain Ratio

Measurement. NCI Thesaurus. Code C98731.

The determination of the ratio of free kappa light chain compared to free lambda light chain present in a sample. The measurement may be expressed as a ratio or percentage. 